\title{
Facies-Controlled Modeling for Permeability of Tight Gas Reservoir Based on Hydrodynamic and Geophysics Characteristics
}

\author{
Peng Yu \\ Guangxi Colleges and Universities Key Laboratory of Beibu Gulf Oil and Natural Gas Resource Effective Utilization, \\ School of Petroleum and Chemical, Beibu Gulf University, Qinzhou 535000, China \\ Correspondence should be addressed to Peng Yu; developoil@163.com
}

Received 21 October 2021; Revised 26 December 2021; Accepted 13 January 2022; Published 28 January 2022

Academic Editor: Ye Zhang

Copyright (c) 2022 Peng Yu. This is an open access article distributed under the Creative Commons Attribution License, which permits unrestricted use, distribution, and reproduction in any medium, provided the original work is properly cited.

Due to poor physical properties and strong heterogeneity of Daniudi tight gasfield (China), traditional methods are not ideal for predicting reservoir permeability. Based on geoscience data mining algorithms and modeling techniques, this parameter is predicted and characterized from a new perspective. The high precision hydraulic unit information was outputted by the BP neural network and the interwell database was predicted by sequential indicator simulation based on the logging and core data, the exponential and power law relationship functions were selected to participate in the construction of the permeability model. The results showed that the facies-controlled modeling system for permeability based on the hydrodynamic characteristics of tight gas reservoirs could effectively improve the accuracy of reservoir prediction, and the logging information in the longitudinal direction and the facies information in the plane were combined by the hydraulic unit.

\section{Introduction}

In recent years, in case of the gradual increase in the scale of exploration and development of tight oil and gas reserves, the reservoir characterization methods have become more abundant [1-3]. Permeability is an important parameter for the evaluation of this type of reservoir, and the acquisition of its accurate value directly affects the results of the evaluation of heterogeneity and the design of scheme [4-6]. If the data points are unified for regression calculation of the permeability-porosity model, the weakly producing pores and invalid reservoirs could easily be classified into the same category $[7,8]$. The disadvantages of this method are particularly obvious in the evaluation process of strongly heterogeneous reservoirs [9-11]. In recent years, various data mining and deep learning algorithms have attracted attention from reservoir engineers due to their excellent calculation ability $[12,13]$, and this type of algorithms have great potential for improving accuracy [14]. The neural network technology is widely used in the data mining field for the prediction of hydraulic unit (HU)/permeability on the single-well scale, especially BP network. BP network has strong nonlinear mapping capabilities and good effect in solving problems of complex reservoir classification.

Tight gas reservoir has the strong heterogeneity in the distribution of throats-pores environment, and the pores' geometrical characteristic could not only constraint physical properties of reservoir geological body but also directly affect the recovery of tight gasfield $[15,16]$. The target area has poor microstructure, complex logging response, and poor correlation between overall porosity and permeability. Therefore, the traditional methods were abandoned, and the geoscience data mining algorithms were applied to solve the prediction problem of permeability, and the permeability distribution was characterized through the optimized porepermeability function based on the platform of modeling software [17-23]. The result could effectively eliminate the interference of weak signal-to-noise ratio and improve the prediction accuracy of the model. Generally, the HU/permeability prediction of well trajectory and interwell space were usually two independent tasks; in this study, the prediction work on the vertical and plane scale was innovatively combined; the BP neural network and faciescontrolled simulation system could directly provide an 
important reference for the prediction and evaluation of related parameters of the same type of reservoirs.

\section{Research Background}

2.1. Geological Setting. The target area is located in the northeast of the Ordos Basin, China, and its construction location is in the northern section of the Yishan Slope (Figure 1). The slope range is about $6-9 \mathrm{~m} / \mathrm{km}$, and the dip angle ranges from $0.3^{\circ}$ to $0.6^{\circ}$. This is a monoclinic structure high in the northeast and low in the southwest with sporadic development of nose-like uplifts. The geological characteristics of the $\mathrm{H}_{3}$ gas-bearing reservoir were studied based on the sedimentary and stratigraphic data of the XiaohaotuDa16 well group, Daniudi gasfield. The $\mathrm{H}_{3}$ reservoir was divided into two layers $\left(\mathrm{H}_{3}^{1}\right.$ and $\left.\mathrm{H}_{3}^{2}\right)$ according to the rock electricity and cycle differences. The sedimentary environment belongs to river sedimentation, and the lithology of the reservoir was composed of gravel sandstone, medium-fine sandstone intercalated with siltstone. The degree of particle sorting was medium-poor.

\subsection{Mathematical Background}

2.2.1. Hydrodynamic Parameters and Permeability Characterization. According to the geological settings, various reservoir characterization parameters have different adaptability. The target area has the characteristics of low permeability, compactness, large seepage changes, and complex pore structure. In the process of constructing the traditional porosity-permeability logarithm linear model, the trend line has segmented characteristics, which will affect the accuracy of the overall permeability prediction model inevitably (Figure 2). And then, the flow zone indicator $\left(I_{F Z}\right)$ and reservoir quality index $\left(I_{R Q}\right)$ were selected to participate in the prediction and characterization research [24]. Amafule et al. [25] conceptualize the pore throat into a series of capillaries and applied the hydrodynamic method to divide the geometric pore units on the basis of permeability changes:

$$
\begin{aligned}
\log I_{R Q} & =\log \varnothing_{z}+\log I_{F Z}, \\
k & =1014\left(I_{F Z}\right)^{2}\left[\frac{\varnothing_{e}^{3}}{\left(1-\varnothing_{e}\right)^{2}}\right],
\end{aligned}
$$

where $I_{F Z}$ reflects the characteristics of rock pores and pore throat and mineral structure, $\mu \mathrm{m}$ and $I_{R Q}$ characterizes the seepage capacity of the reservoir, $\mu \mathrm{m}$ [26].

2.2.2. BP Neural Network. The BP neural network is composed of an input layer, a hidden layer, and an output layer. The layers are connected by weights. The network training and learning process includes error back propagation and forward propagation of information. The external information is collected and passed to the hidden layer (each neuron node) through the input layer and further passed to the output layer under the action of the excitation function

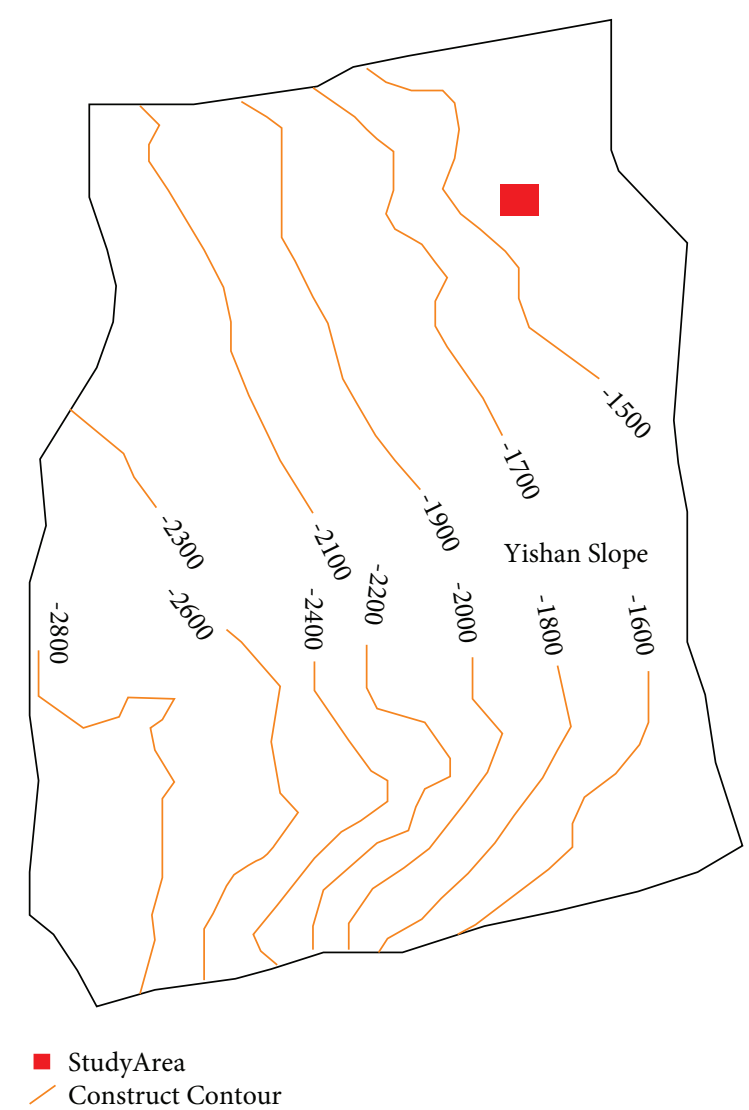

FIGURE 1: Location of the study area and structure distribution.

to complete a forward propagation. The system will enter the back propagation process if the output is inconsistent with expectations. The general principle is to reduce the error between the output and the expectation, the hidden layer and the input layer are conveyed error information through a mode in which the error gradient is gradually reduced, and the weights are also adjusted at the same time. The following formula is the error function expression:

$$
E=\frac{1}{2} \sum_{k=1}^{l}\left(d_{k}-O_{k}\right)^{2},
$$

where $\left(d_{k}-O_{k}\right)$ corresponds to the difference between the expected and output results. In the back propagation process, the adjustment calculation expression of the weight $w$ is as follows:

$$
\Delta w=-\eta\left(\frac{\partial E}{\partial w}\right),
$$

where the proportional coefficient is represented by a constant, which is the learning rate of the network, and the negative sign represents the gradual decrease of the gradient.

\section{Hydraulic Unit Modeling}

3.1. The Hydraulic Unit Identification of the Core Samples. $I_{F Z}$ of core samples was calculated based on the parameters of porosity and permeability, and then the cluster analysis of 


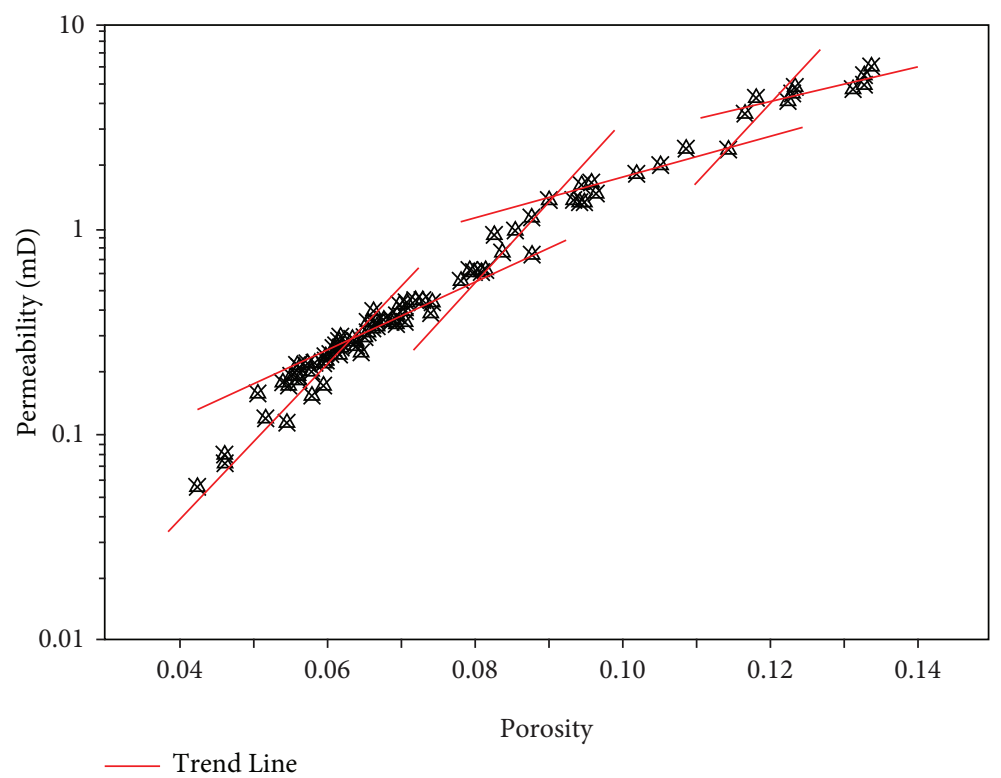

Figure 2: Porosity and permeability relationship and corresponding trend lines.

the sum of squared deviations method was applied to perform calculations since the sum of squares of deviations of the same class is small and the sum of squares of deviations between classes is large, and this method could show a good effect on the classification of hydraulic units [27-30]. Finally, the hydraulic units in the target area were divided into 4 types. From Figure 3, each type of hydraulic unit corresponds to a fitted trend line with a slope of 1 , and the intercept of the trend line is the average $I_{F Z}$ value of this type

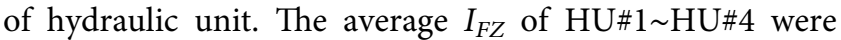
$1.3497,1.1889,0.9967$, and 0.8367 , respectively. Because the reservoir is tight and the range of porosity-permeability parameters is small, the difference between the average values of $I_{F Z}$ is also relatively small, but it does not affect the area division of different hydraulic units on the chart of standard porosity-reservoir quality index.

\subsection{Neural Network Pattern Recognition Technology for} Single-Well. Loggings are the comprehensive parameters that can reflect the geophysical characteristics of the reservoir, and the parameters were introduced into the training process of the artificial neural network. The entire recognition network was composed of input, output, and hidden layer neuron systems under the artificial neural network technology. Logging parameters (RT, AC, SP, GR, and DEN) of the target area were used as input elements, and four types of hydraulic unit types were used as output elements to perform BP network pattern recognition and prediction. The schematic diagram is shown in Figure 4.

According to the empirical formula and the test deduction results, the number of hidden layer neurons was finally determined to be 15 , and the sum of the test and validation data weights was set to be $30 \%$. Among them, several key parameters were set as follows: the network learning rate is 0.1 ; the allowable error is 0.001 , and the maximum number of training is 1000 (see Table 1). The network training was stopped execution when the training effect reaches the set requirements.

From the results, the positive judgment rate of test set on the confusion matrix was as high as $95.50 \%$, and the positive judgment rate of the overall set was $98.20 \%$ (Figure 5).

The training network was saved, and the sample points were randomly selected for the test on the effect of network prediction. Test results are shown in Figure 6. It can be seen that the statistical frequency of $\mathrm{HU}$ prediction on the main diagonal occupies a large proportion, and the overall prediction effect was close to $85 \%$ with the environment of insufficient data points. Among them, the prediction accuracy of $\mathrm{HU} \# 1, \mathrm{HU} \# 2$, HU\#3, and HU\#4 were $50 \%, 75 \%$, $81.82 \%$, and $90.48 \%$, respectively. And then, the uncored section of the single well and the uncored well were predicted by the network which provides sufficient hydraulic unit information of single well for the next spatial modeling of the hydraulic unit.

Then, the spatial model was further constructed by the sequential indicator simulation method based on the predicted results which were treated as 4 types of discrete variables [31]. The search path values were estimated in each layer and unit, and the layers were simulated under the fitting environment of the variogram. The spatial geological body of $\mathrm{H}_{3}$ was established finally.

\section{Permeability Model}

After determining the spatial distribution model of hydraulic units in the target area, the regression calculation of porosity-permeability parameters was performed according to each type of hydraulic unit. Thus, each regression model represents the permeability prediction model of each type of hydraulic unit, and then the permeability of each model grid is calculated by the prediction model through the software 


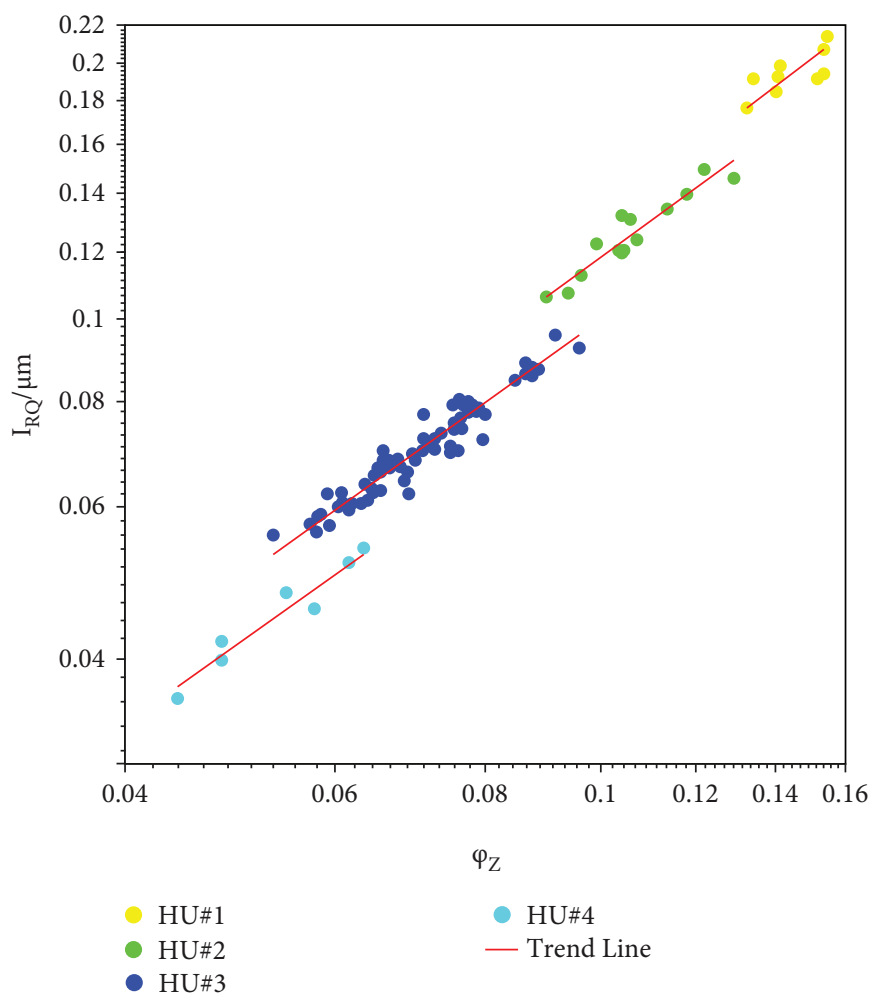

Figure 3: The clustering results of hydraulic units and the fitting trend lines of each unit.

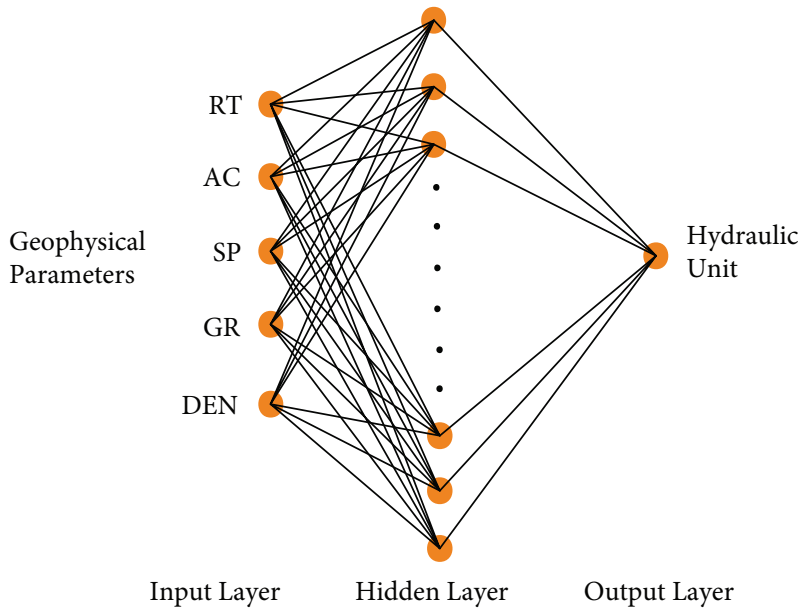

FIgURE 4: Schematic diagram of BP network structure.

platform of Petrel. Because the porosity model was predicted under facies-controlled modeling conditions, the permeability prediction model calculated based on the porosity model was also constrained by the facies-controlled environment on the plane.

4.1. Establishment of the Permeability Prediction Model. Analyzing the past prediction results of physical property parameters, it can be found that it is easy to produce pessimistic results by processing the data to predict the permeability according to the traditional linear method. The main reason is that the part of high-permeability and low- permeability showed obvious heterogeneity changes, which ultimately affects the regression model $[32,33]$. Therefore, this study abandoned the traditional data processing methods and matched the classification results of the hydraulic unit to the permeability model; the porosity-permeability regression model based on each type of unit is as follows:

$$
\begin{aligned}
& \text { HU\#1: } \quad k=0.3536 e^{20.7420 \varnothing}\left(R^{2}=0.7519\right), \\
& \text { HU\#2: } \ln k=7.9770+3.2161 \ln \varnothing\left(R^{2}=0.9362\right), \\
& \text { HU\#3: } \ln k=7.2743+3.0815 \ln \varnothing\left(R^{2}=0.9657\right), \\
& \text { HU\#4: } \ln k=7.2989+3.2109 \ln \varnothing\left(R^{2}=0.9715\right),
\end{aligned}
$$

where $k$ is permeability $\left(10^{-3} \mu \mathrm{m}^{2}\right)$ and $\varnothing$ is porosity.

The optimal exponential and power law relationship functions were used in each type of hydraulic unit system to predict the permeability based on the modeling software platform. And then, the 3D-geological body of predicted permeability was constructed.

\subsection{Validation of the Permeability Model}

4.2.1. Model Verification on the Plane. From the perspective of the plane characteristics of the model, the distribution of the permeability of the small layer corresponds well to the distribution trend of the sand body in the target area. Variogram information was output based on the difference between high-energy and low-energy zones of permeability (Figure 7) (range of 20 deg: $2886.8677 \mathrm{~m}$, sill: 0.8732, nugget: 
TABLE 1: Important parameters of the BP network learning process.

\begin{tabular}{lcccccc}
\hline Weights & $\begin{array}{c}\text { Learning } \\
\text { Train set } \\
(\%)\end{array}$ & $\begin{array}{c}\text { Validation set } \\
(\%)\end{array}$ & $\begin{array}{c}\text { Test set } \\
(\%)\end{array}$ & $\begin{array}{c}\text { Allowable } \\
\text { error }\end{array}$ & $\begin{array}{c}\text { Maximum number of } \\
\text { training }\end{array}$ & $\begin{array}{c}\text { Number of hidden layer } \\
\text { neurons }\end{array}$ \\
\hline 70 & 10 & 20 & $1.00 \times 10^{-1}$ & $1.00 \times 10^{-3}$ & 1000 & 15 \\
\hline
\end{tabular}

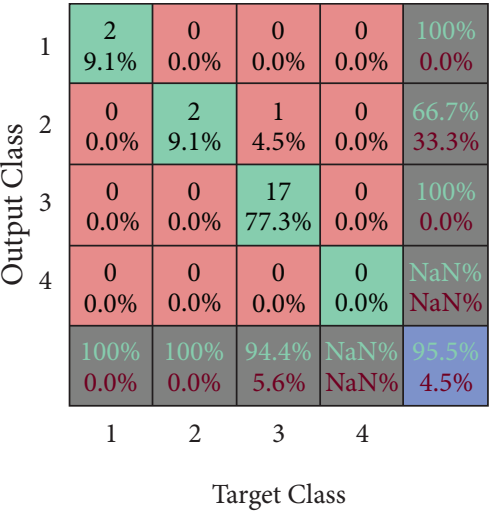

(a)

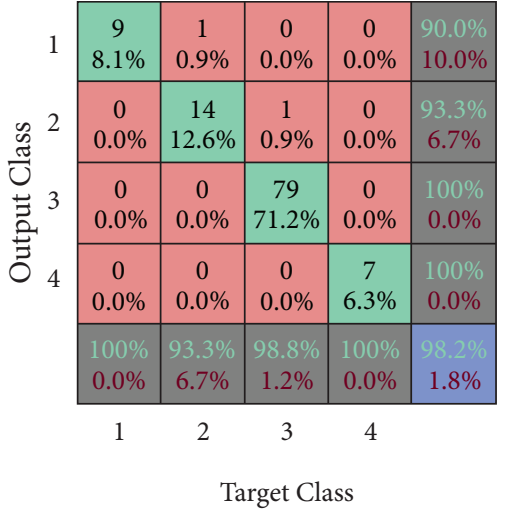

(b)

Figure 5: Confusion matrix analysis diagram of classification model prediction results. (a) Test set. (b) Overall set.

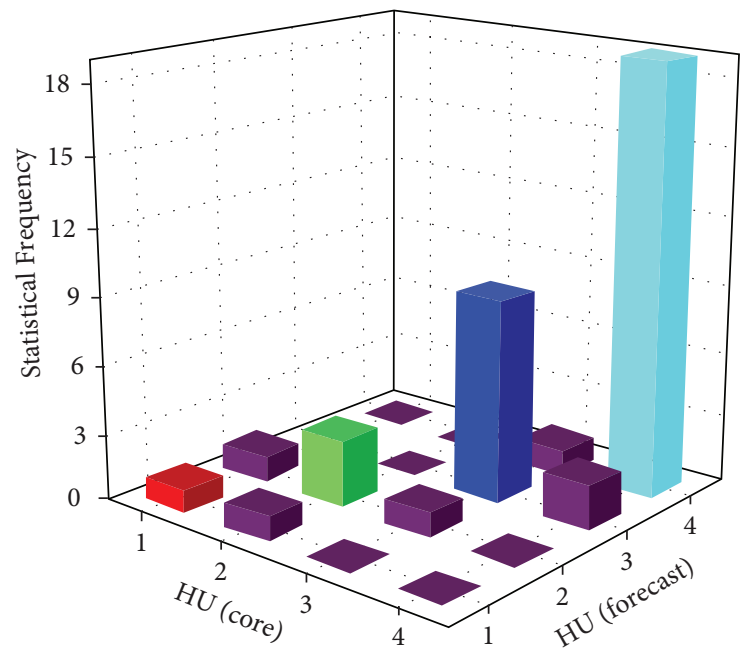

Figure 6: Statistical frequency of HU prediction.

0.1124 ; range of $70 \mathrm{deg}: 1000.2383 \mathrm{~m}$, sill: 0.8710 , nugget: 0.0615), the variogram characteristics were consistent with the sedimentary characteristics, and the direction of maximum range (arrow direction in Figure $7(\mathrm{a})$ ) was consistent with the provenance direction.

The $1^{\text {st }}$ layer of the geological body was randomly selected to draw the relationship chart of the porosity-permeability-facies, from Figure 8, and the porosity and permeability were interrelated in three dimensions. Random point selection was performed in the interpolation area between the model wells, and the distribution law of the permeability value was consistent with the geological setting. According to the plane distribution of the facies, it can be seen that the high permeability area matched the types of microfacies with good physical properties such as channel bar and point bar. The distribution characteristics of the prediction model on the plane were reasonable except for a few extreme values that were not controlled by the well points.

4.2.2. Model Verification on the Vertical. From the calculation results of the model's vertical variogram (range on the vertical: $4.0198 \mathrm{~m}$, sill: 0.9385 , nugget: 0.1639 ), the range was consistent with the scale of sand body development. The overall fluctuation characteristics of the semivariance values were stable (Figure 9). However, it is worth noting that when the curve passes through the origin, it jumps directly to a 


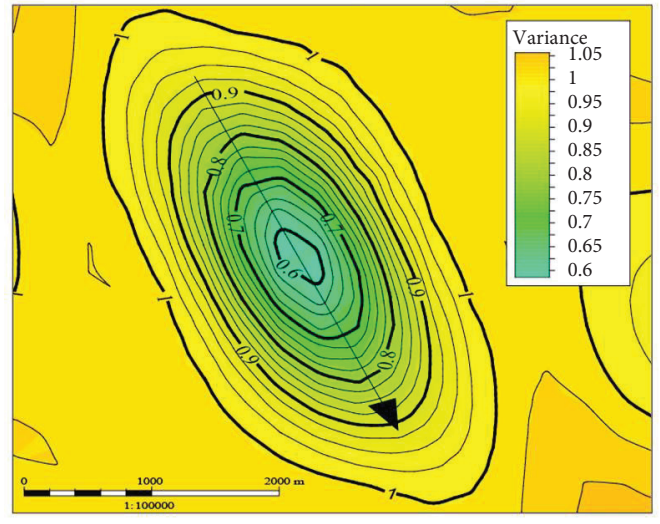

(a)

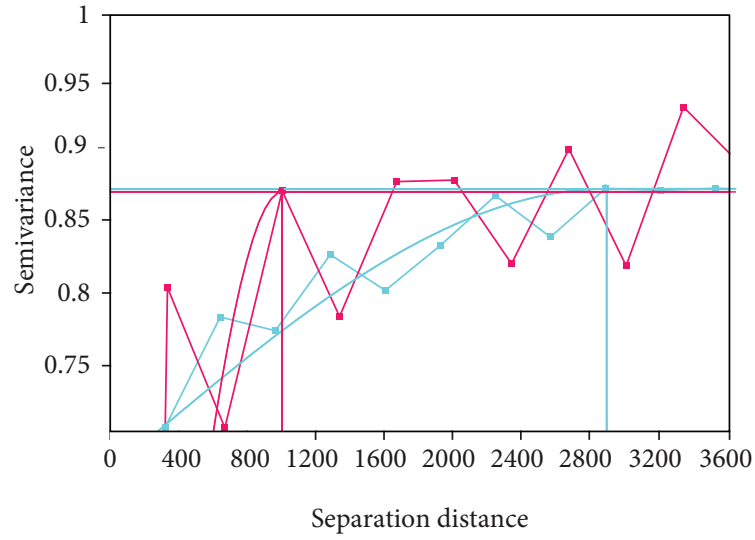

- Var. from Perm (-20 deg)

- Sample var. from Perm (-20 deg)

$\rightarrow$ Var. from Perm (70 deg) (70 deg)

(b)

FIgURE 7: Composite chart of the plane variogram figure of the predicted model. (a) Plan view of variogram in the XY direction of the model (the direction of the arrow is the direction of maximum range). (b) Model output variation fitting graph.

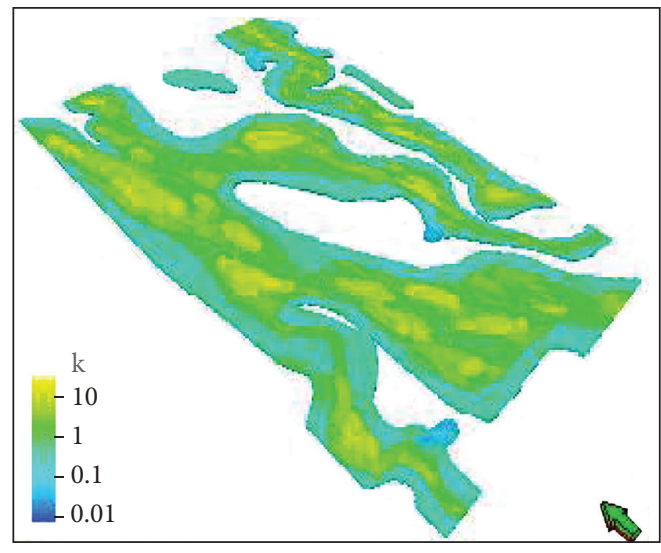

(a)

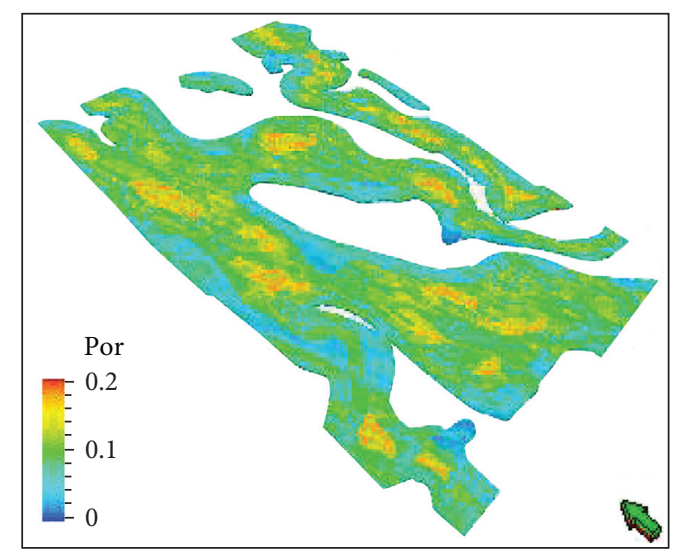

(b)

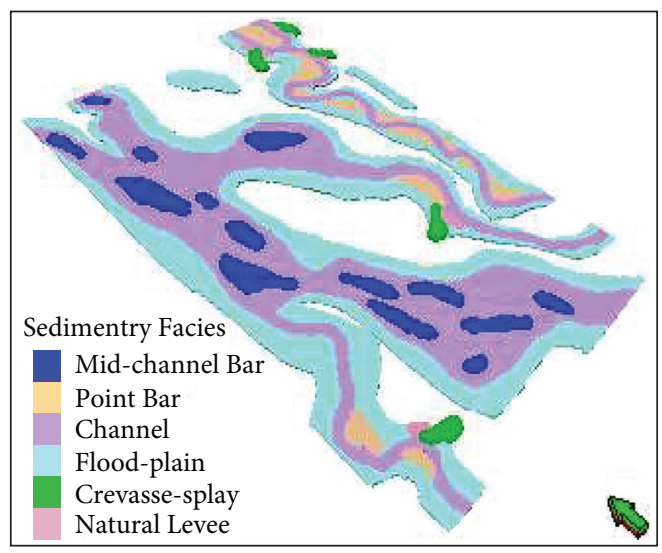

(c)

FIGURE 8: Relationship among porosity, permeability, and facies. (a) Distribution of permeability of the $1^{\text {st }}$ layer. (b) Distribution of porosity in the $1^{\text {st }}$ layer. (c) Distribution of sedimentary facies in the $1^{\text {st }}$ layer. 


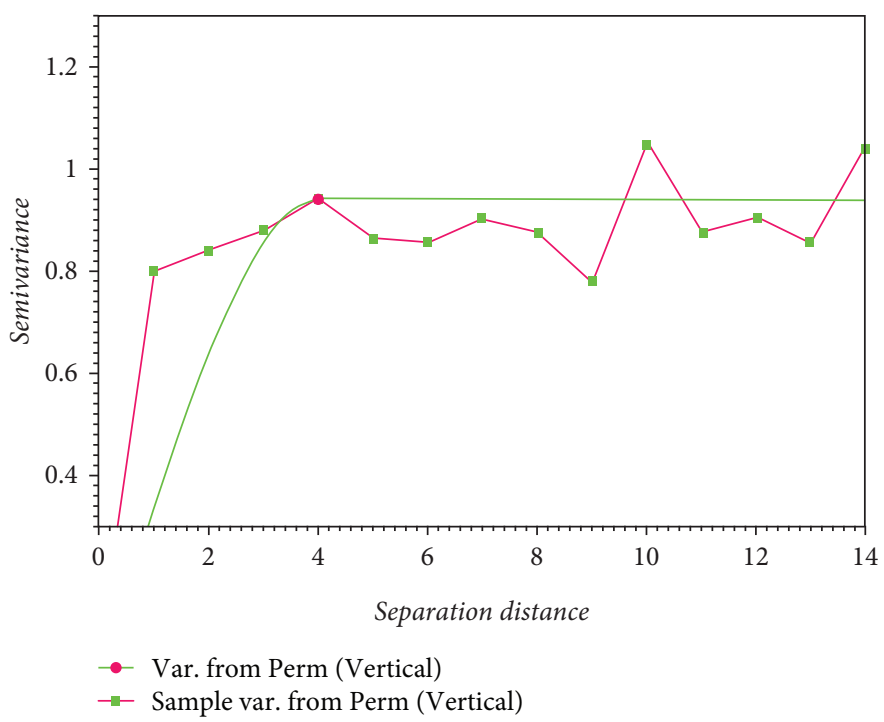

Figure 9: Variogram of vertical direction.

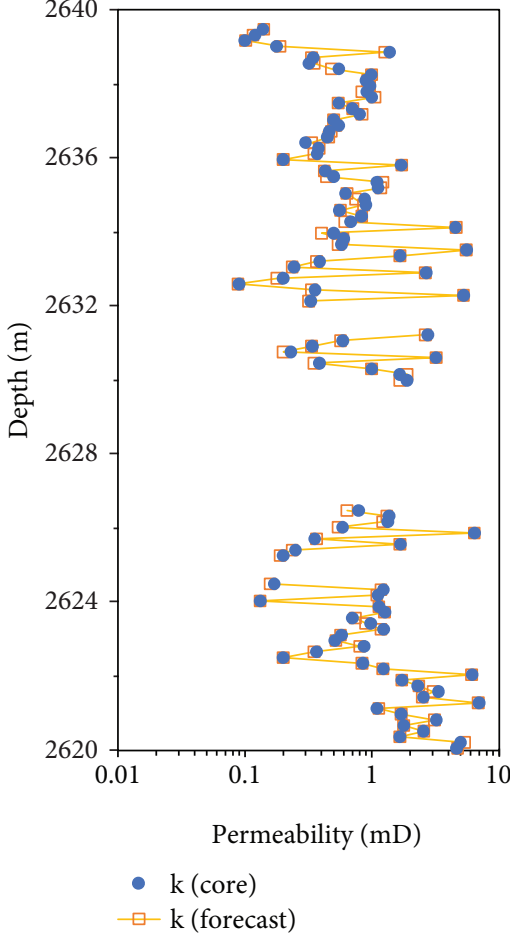

(a)

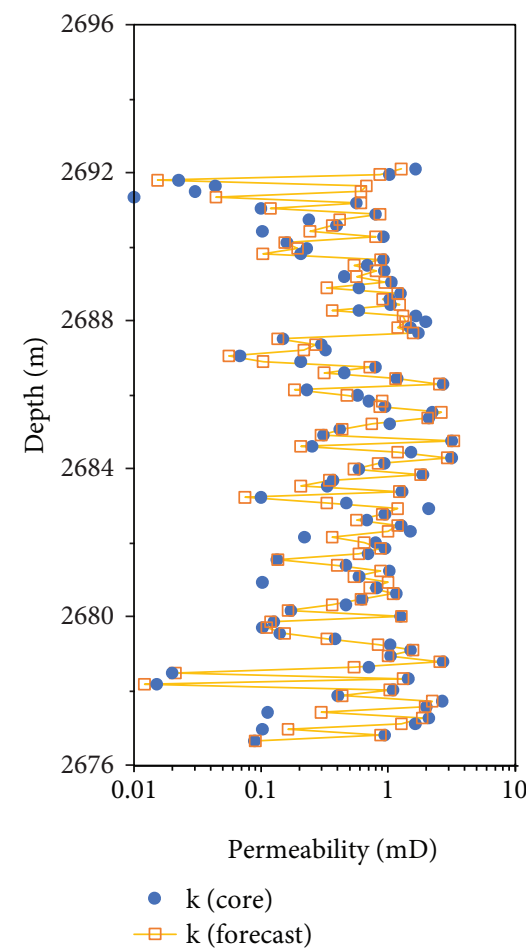

(b)

FIgUre 10: Profile of permeability prediction. (a) Well D52. (b) Well D30.

high value interval above 0.8000 . The jump-like fluctuation of the semivariance value at the origin reflects the heterogeneity which was also consistent with the actual strong heterogeneity of the target reservoir on the vertical direction.

At the same time, the wells D52 and D30 were selected to randomly eliminate, and the previous modeling ideas were repeated to reconstruct the model and output the predicted permeability profiles on the trajectories of these two wells (Figure 10). Comparing the predicted permeability data with the core test data of the two wells, it can be seen that the repeated action did not interfere with the accuracy of the model, and the predicted permeability information of the two wells were basically consistent with the core data. This comparison also verified the reliability of the model information database. 


\section{Results and Discussion}

The heterogeneity of tight gas reservoirs is usually serious, and conventional prediction methods often cannot accurately reflect the permeability characteristics of the reservoir. In the study of Izadi et al., HFU model was applied to a lowpermeability reservoir based on a series core data, and the model identified more flow units and also predicted moreaccurate permeability/porosity relationships [34]. Lin et al. conducted a tight reservoir permeability prediction based on an artificial neural network for a small sample environment, and the prediction results were good [35]. Unlike the above neural network model, the permeability was used as an indirect output parameter in this study, and the BP network with higher accuracy was trained to predict the types of hydraulic units. The three-dimension of the hydraulic unit was established by the sequential indicator simulation technology, and on the basis of the geological body, the permeability mode grids were fully calculated based on the porosity-permeability relationship of each unit. The model was controlled by high precision hydraulic unit on the vertical and sedimentary facies on the plane. The final permeability prediction system was more reliable, which could provide a powerful force for next numerical simulation work and related evaluation work.

\section{Conclusions}

The hydrodynamic and geophysical characteristics of tight gas reservoirs were fully considered by this study, and its application effect was better. The conclusion is as follows:

(1) The flow zone indicator and the cluster method of the sum of square deviations were selected to classify the reservoir hydraulic units into 4 types.

(2) The best network was trained; in the results of statistical frequency of $\mathrm{HU}$ prediction, the overall prediction effect was close to $85 \%$, and the prediction accuracy of HU\#4 reached $90.48 \%$.

(3) By calculating the variogram of the permeability on the plane and vertical, the reliability of the predicted geological body was verified; the rationality of the model space was also reflected by the analysis results of the porosity-permeability-facies and the repeated action.

(4) The facies-controlled modeling method for permeability based on hydrodynamic and geophysics characteristics can improve prediction accuracy. It provides an effective method for spatial permeability prediction using sedimentary facies and logging data.

\section{Data Availability}

The data used to support the findings of this study are included within the article.

\section{Conflicts of Interest}

The author declares that there are no conflicts of interest.

\section{Acknowledgments}

The author would like to thank the Natural Science Foundation of Guangxi Province and the Thousands Elite Plan Foundation for excellent support. This work was supported by the Natural Science Foundation of Guangxi Province (grant numbers: 2016GXNSFBA380180, 2017GXNSFAA198105, and 2021GXNSFAA220012) and the Thousands Elite Plan Foundation (grant number: GJSF(2019)81).

\section{References}

[1] D. Albrecht and V. Reitenbach, "Investigations on fluid transport properties in the North-German Rotliegend tight gas sandstones and applications," Environmental Earth Sciences, vol. 73, no. 10, pp. 5791-5799, 2015.

[2] X. F. Ren, Y. N. Ma, and J. Wei, "Evaluation of reservoir pore structure is core of evaluation of tight sandstone reservoirs," World Well Logging Technology, vol. 40, pp. 27-34, 2019.

[3] P. Zuloaga-Molero, W. Yu, and Y. Xu, "Simulation study of $\mathrm{CO} 2-\mathrm{EOR}$ in tight oil reservoirs with complex fracture geometries," Scientific Reports, vol. 6, pp. 1-11, 2016.

[4] A. A. Bhatti, A. Ismail, and A. Raza, "Permeability prediction using hydraulic flow units and electrofacies analysis," Energy Geoscience, vol. 4, pp. 1-11, 2020.

[5] A. S. Ziarani and R. Aguilera, "Knudsen's permeability correction for tight porous media," Transport in Porous Media, vol. 91, no. 1, pp. 239-260, 2012.

[6] C. N. Zou, S. Z. Tao, and L. H. Hou, Unconventional Oil and Gas Geology, Geological Publishing House, Beijing, China, 2013.

[7] A. Amann-Hildenbrand, J. P. Dietrichs, and B. M. Krooss, "Effective gas permeability of Tight Gas Sandstones as a function of capillary pressure - a non-steady-state approach," Geofluids, vol. 16, no. 3, pp. 367-383, 2016.

[8] L. Zeng, "Microfracturing in the upper triassic sichuan basin tight-gas sandstones: tectonic, overpressure, and diagenetic origins," AAPG Bulletin, vol. 94, no. 12, pp. 1811-1825, 2010.

[9] C. Jing, Z. Q. Song, and C. S. Pu, "Refined permeability of tight gas reservoir based on petrophysical facies classification: taking the study of tight gas reservoir permeability in the eastern of Sulige for an example," Progress in Geophysics, vol. 28, pp. 3222-3230, 2013.

[10] S. X. Liu, J. H. Zhong, and X. G. Liu, "Gas transport mechanism in tight porous media," Natural Gas Geoscience, vol. 25, pp. 1520-1528, 2014.

[11] X. T. Yuan, S. M. Peng, and C. Y. Lin, "An interpretation method for permeability based on flow units and its applicability," Acta Petrolei Sinica, vol. 26, pp. 78-81, 2005.

[12] L. Gan, Y. Wang, and X. Luo, "A permeability prediction method based on pore structure and lithofacies," Petroleum Exploration and Development, vol. 46, pp. 935-942, 2019.

[13] L. Q. Zhu, C. Zhang, and C. M. Zhang, "A new and reliable dual model and data-driven TOC prediction concept: a TOC logging evaluation method using multiple overlapping methods integrated with semi-supervised deep learning," Journal of Petroleum Science and Engineering, vol. 188, pp. 1-23, 2020a.

[14] L. Q. Zhu, C. Zhang, and C. M. Zhang, "Forming a new small sample deep learning model to predict total organic carbon content by combining unsupervised learning with semisupervised learning," Applied Soft Computing Journal, vol. 83, pp. 1-23, 2019. 
[15] W. Lin, X. Li, and Z. Yang, "Multiscale digital porous rock reconstruction using template matching," American Geophysical Union, vol. 1, pp. 1-20, 2019.

[16] X. L. Zhao, Z. M. Yang, and W. Lin, "Study on pore structures of tight sandstone reservoirs based on nitrogen adsorption, high-pressure mercury intrusion, and rate-controlled mercury intrusion," Journal of Energy Resources Technology, vol. 141, pp. 1-11, 2019.

[17] O. K. Akande, O. S. Olatunji, and O. T. Owolabi, "Comparative analysis of feature selection-based machine learning," in Proceedings of the SPE Saudi Arabia Section Annual Technical Symposium and Exhibition, pp. 1-12, Editorial Committees of the Society of Petroleum Engineers, AlKhobar, Saudi Arabia, April 2015.

[18] L. Ali, S. Bordoloi, and H. S. Wardinsky, "Modeling permeability in tight gas sands using intelligent and innovative data mining techniques," in Proceedings of the SPE Annual Technical Conference and Exhibition, pp. 1-11, Editorial Committees of the Society of Petroleum Engineers, Denver, CO, USA, September 2008.

[19] Y. Gao, Y. S. Wang, and X. J. Li, "Classification method of tight sandstone based on pore throat structure: a case study of Paleogene in Jiyang Depression," Petroleum Geology and Recovery Efficiency, vol. 26, pp. 32-41, 2019.

[20] W. Lin, X. Li, and Z. Yang, "A new improved threshold segmentation method for scanning images of reservoir rocks considering pore fractal characteristics," Fractals, vol. 26, pp. 1-9, 2018.

[21] S. I. Nashawi and A. Malallah, "Improved electrofacies characterization and permeability predictions in sandstone reservoirs using a data mining and expert system approach," Petrophysics, vol. 50, pp. 250-268, 2009.

[22] G. R. Shi, Study of Data Mining and Knowledge Discovery, Petroleum Industry Press, Beijing, China, 2012.

[23] L. Q. Zhu, C. M. Zhang, and Z. S. Zhang, "High-precision calculation of gas saturation in organic shale pores using an intelligent fusion algorithm and a multi-mineral model," Advances in Geo-Energy Research, vol. 4, pp. 135-151, $2020 \mathrm{~b}$.

[24] Y. Li and J. M. Liu, The Principle and Method of Flow Unit Study, Geology Press, Beijing, China, 2005.

[25] J. O. Amafule, M. Altunbay, and T. Djebbar, Enhanced Reservoir Description: Using Core and Log Data to Identify Hydraulic(flow) Units and Predict Permeability in Uncored Intervals/wells. Proceedings of the SPE Annual Technical Conference and Exhibition, pp. 205-220, Editorial Committees of the Society of Petroleum Engineers, Houston, TX, USA, 1993.

[26] A. Mirzaei, H. Saboorian, and P. Pourafshary, "Improved method to identify hydraulic flow units for reservoir characterization," Energy Technology, vol. 3, pp. 726-733, 2015.

[27] C. Aguilar, A. H. Govea, and G. Rincon, Hydraulic Unit Determination and Permeability Prediction Based on Flow Zone Indicator Using Cluster Analysis. SPE Latin American and Caribbean Petroleum Engineering Conference, pp. 1-14, Editorial Committees of the Society of Petroleum Engineers, Maracaibo, Venezuela, 2014.

[28] J. Lai, G. W. Wang, and M. Chen, "Pore structures evaluation of low permeability clastic reservoirs based on petrophysical facies: a case study on Chang 8 reservoir in the Jiyuan Region, Ordos Basin," Petroleum Exploration and Development, vol. 40, pp. 566-573, 2013.

[29] J. Ma, "The study on the reservoir characteristics and flow units of Yanchang formation Chang 63 reservoir in Huaqing area," Northwest University, Xi'an, China, 2013.
[30] W. Xue, SPSS Statistical Analysis Method and Application, Publishing House of Electronics Industry, Beijing, China, 2013.

[31] S. Li, The Research and Application of Sequential Indicator, Jilin University, Changchun, China, 2015.

[32] W. M. Wang, "Application of log parameter quantification technology to interpretation of the physical properties of the Putaohua reservoir in the Yushulin oilfield," Oil \& Gas Geology, vol. 30, pp. 230-235, 2009.

[33] Q. B. Yan, M. J. Chen, and J. Wang, "Correlation among permeability, porosity and pore throat radius of carbonate reservoirs," Natural Gas Industry, vol. 35, pp. 30-36, 2015.

[34] M. Izadi and A. Ghalambor, "A new approach in permeability and hydraulic-flow-unit determination," SPE Reservoir Evaluation and Engineering, vol. 8, pp. 257-264, 2013.

[35] L. Lin, J. Wang, and X. J. Liu, "Prediction for permeability of tight reservoir based on artificial neural network," Well Logging Technology, vol. 45, pp. 179-184, 2021. 